\title{
Research on the Measure to Restrain the Fog Haze in Fushun
}

\author{
Liu Min ${ }^{1}$, Zhang Wei ${ }^{1}$, Guo Junping ${ }^{1}$, Li Wei $^{1}$, Sui Yibing ${ }^{2}$, Liu Junde ${ }^{2}$, Diao Yu ${ }^{2}$, Su Yang ${ }^{1}$, \\ Wang Shuai ${ }^{1}$, Yuan Chengye ${ }^{1}$, Sun Jiaxin ${ }^{1}$, Han Weihua ${ }^{1}$
}

${ }^{1}$ Fushun Power Supply Company, Liaoning Electric Power Company Limited, State Grid, China

${ }^{2}$ Liaoyang Power Supply Company, Liaoning Electric Power Company Limited, State Grid, China

Keywords: fog haze; electrical equipment; precautionary measure; PM2.5

\begin{abstract}
Fog haze weather frequently appears in recent years. Fog haze not only makes the travel inconvenient, also has a harmful effect on body. Fog haze brings serious security hidden danger to the power grid safety and power equipment operation. The lightest situation is shortening the time of saturated salt density, and pollution accident is the heaviest situation caused power equipment. This paper explains the concept of fog haze, TSP, PM10, PM2.5, and the relationship between them. he danger and source of haze are discussed. Aiming at the problem of haze, power sector vigorously promoted the new model of energy consumption, which is electric substituted for coal and electric substituted for oil. Advocate the transport sector, enterprises and citizens to use electric cars and electric buses. Kitchen and household heating realize electrified. Reduce pollutant emission and restrain haze weather to ensure the safety of electric power equipment to normal.
\end{abstract}

\section{Introduction}

The "fog haze" has been annual keywords in 2013.In January, the country had appear big fog four times, totally covered 30 provinces and cities, including Shenyang and Fushun).On January 4th, 2014, the national disaster reduction, department of civil affairs for the first time will be a health hazard of haze weather into natural disaster in 2013.In February 2014, Xi Jinping in Beijing pointed out that the priority to control the PM2.5 is to deal with fog pollution and improve air quality. Take measures to reduce coal, strictly control the car, adjust industry, strengthen the management, defense from spreading and governance in accordance with the laws, gathered in key areas, strictly index evaluation, and strengthen the supervision of environmental law enforcement and responsibility seriously.

\section{The meaning of the fog haze}

Fog haze just as its name implies is fog and haze. Fog is composed of a suspended in the air near the ground aerosol system composed of small water droplets or ice crystals. The haze is the aerosol system that composed of dust in the air, sulfuric acid, nitric acid particulate matters, as shown in Fig 1 and Fig 2.

In a nutshell, fog is tiny water droplets in the air, moisture content is $90 \%$ or more, rendering white, milky white, or cyan, and haze is the tiny particles in the air, moisture content is below $80 \%$, rendering yellow or orange gray. When the water content of air is between $80 \%$ and $90 \%$ is the haze, as shown in Fig 3[1].

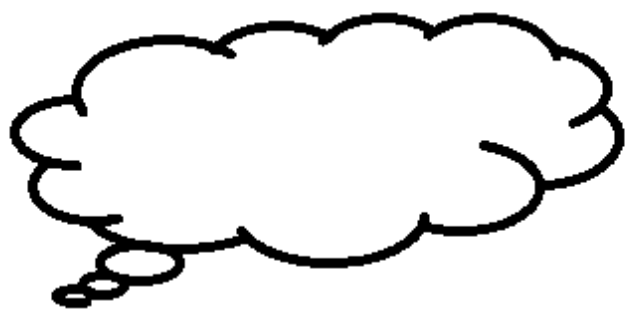

Fig.1 Fog

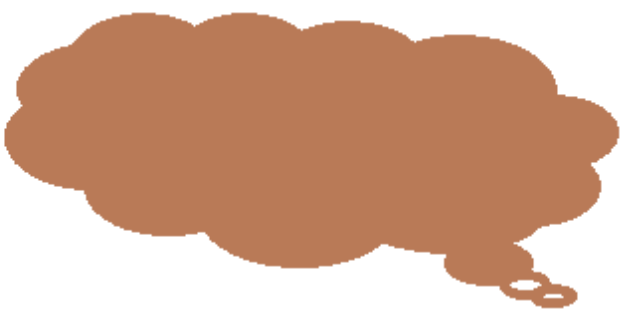

Fig.2 Haze 


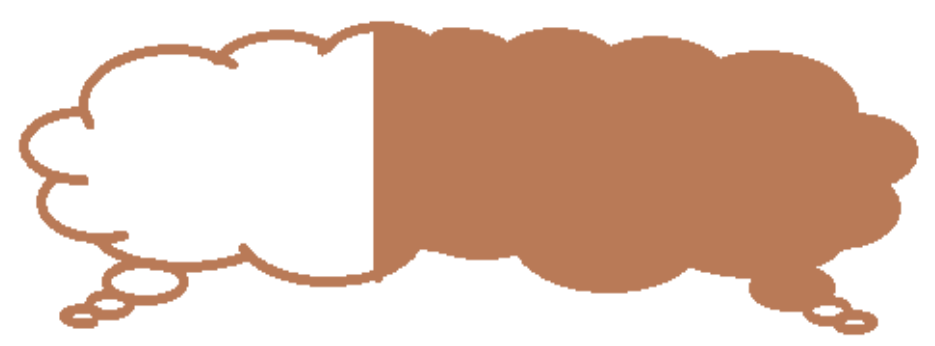

Fig.3 Fog haze which water content of air is between $80 \%$ and $90 \%$

\section{The meaning of the PM2.5}

The total suspended particulate (also called TSP), refers to the various particulate matter disperse in the atmosphere, which defined as aerodynamic equivalent diameter less than 100 microns particles, the unit is microgram per cubic meter. When the aerodynamic equivalent diameter less than or equal to 10 microns particles, it called PM10. When the particulate greater than that of PM10 particles will be kept out by vibrissa, but the particulate smaller than that of PM10 particles with airflow into the bronchi. So PM10 also called inhalable particle. If the equivalent diameter less than or equal to 2.5 microns is called PM2.5. When the equivalent diameter smaller than that of the PM10 and greater than that of PM2.5 particles, they will be kept out by nasal hairs and respiratory secretions to intercept and is discharged by sputum. When they less than PM2.5, harmful particles can directly into the lungs spore, so it also called back into the lung particles. The main ingredients of fog haze are PM2.5 [2]. As shown in Fig 4.

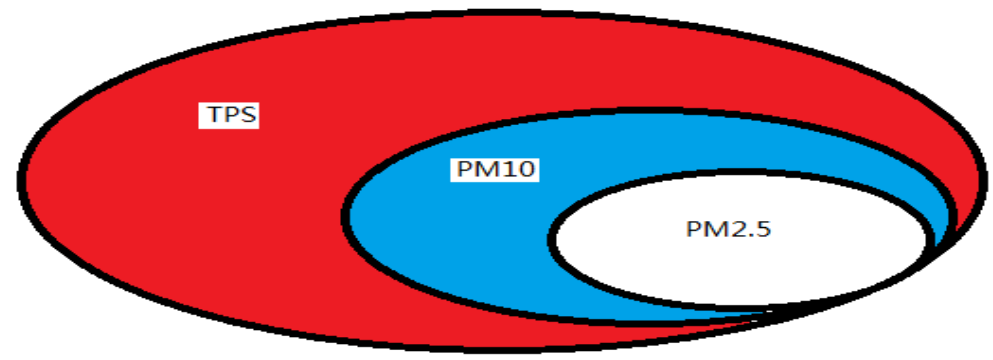

Fig 4 PM2.5 schematic diagram

\section{The source of the fog haze}

The source of the fog haze can be divided into natural and human sources.

Natural sources include the following items:

(1) Pollen and spores from plants, bacteria and virus;

(2) The burning ashes and soot from forest fire;

(3) Dust from volcano eruption;

(4) The dust in the dust weather;

(5)Salt particles threw up by the waves.

Human sources include the following items:

(1)Automobile exhaust, large car that use diesel emissions much PM10, including big bus, the car of each unit, and large transport trucks, etc.

(2) The exhaust gas for heating produced by coal in winter;

(3)The exhaust gas from industrial production, such as metallurgy, kiln and boiler, mechanical and electrical manufacturing industry, and a large number of automobile paint, building materials production furnace combustion emissions;

(4)The dust from sites and roads construction;

(5) Cooking and barbecue lampblack;

(6) Straw burning in fall;

(7)The dust from the building decoration; 


\section{The dangers of fog haze}

First, causing respiratory disease. The composition of haze is very complicated, there are hundreds of different size particles, when it enters the respiratory tract, can lead to diseases such as bronchitis, asthma.

Second, causing cardiovascular and cerebrovascular disease. In the haze weather, the oxygen content is low, that cause chest tightness, shortness of breath and heart beat faster.

Third, causing all sorts of bacterial disease. Because of the fog weather sun exposure is less than the earth, or sun, lead to bacterial viruses reproduce rapidly and cause allergic disease.

Fourth, make the person depressed and lack of energy, etc.

Fifth, prone to traffic accidents. Visibility is low in haze weather. It has great potential safety hazard on the pedestrian and vehicle, which is very dangerous. Similarly, haze weather has bad influence on the railway, aviation, shipping and crop growth[5].

Sixth, the harm to power system. In the serious fog haze power equipments absorb aerosol particles of various salt from haze, and at the same time it is easy to collide and ionization under the electric work. Finally it will lead to an insulation breakdown on the surface of the power equipment. Fog haze is the most easily to cause pollution flashover on power transmission and transformation equipments. Large area pollution flashover accident will cause catastrophic damage to the operation of the power system, mainly display in widespread blackouts. Therefore, fog haze is called "invisible killer" by grid work personnel.

\section{Measures to prevent}

Fushun power supply company established the "configuration in place, every ceramic coating, insulation reinforcement, avoid uncleanness" technology principle for pollution flashover trip and power failure caused by the haze. Dynamic revision the fouling distinguish layout. Measures to prevent are the following items.

(1) In the spring and autumn season, outer insulation of the power equipment can be clear and coated with silica gel fuel to protect the insulation, or the use of reasonable prevention measures such as insulator skirts. TV anti-fouling coating adopt composite insulator that improve the anti-fouling ability of power equipment external insulation in high humidity environment. Reduce the pollution flashover accident in the transmission line and prevent the fog haze weather to affect transmission lines [2].

(2) It spends lots of money to repair electrical equipment fault caused by the pollution flashover. The glass and porcelain are spraying anti-fouling coatings. Make external insulation change into composite insulator with resistant corrupt ability. In serious pollution area, rebuilding, reconstruction and expansion substation must adopt indoor design or totally enclosed combination appliances.

In haze weather, Fushun power Supply Company reinforces to patrol and overhaul. To begin the patrol work, repair emergency lines and inspection equipment work that closely focus on the operation of the transmission line, in a timely manner to eliminate potential safety problems, in order to ensure the safety operation of the grid [3].

\section{Strengthen the power grid construction}

To deal with the damage of haze weather to electrical equipments, Fushun electric power supply company adopt the principle of "configuration, the insulation in place, leave allowance" in high voltage engineering field to strengthen the polluted degree test and external insulation configuration, strengthen power grid construction, accelerate the reform of the distribution network automation, professional repair and maintenance work. To strengthen the safe operation level of power grid, improving wind power and other new energy grid technology to deal with the effects of haze weather on power equipments [3]. 


\section{Conclusion}

Government concerned departments should intensify propaganda; regularly organize activities about environmental protection to arouse people's environmental protection consciousness. Laws and regulations should be set, punish and rectify enterprises of "artificial source" and individuals. Media act the role of the supervision for public opinion, to report the objective and fair social practice, to provide the correct public opinion. Not only to control the artificial source, but also control the occurrence of natural source.

Government concerned departments should also actively cooperate with the electric power department to carry out the new model of the energy consumption "electricity instead of coal, electricity instead of oil and electricity from far away". Advocate the transportation departments, enterprises and public use of electric cars, electric bus, kitchen, home, heating, realize family electrification. To reduce the pollutant emissions, reduce the fog haze weather. When we work together to actively participate in governing the haze, we will fight the haze.

\section{References}

[1] The popular science of China-V vision courier, second's wikipedia

[2] Yu Huayu. High voltage electrical equipment antifouling flash and cleaning with electrical. China Electric Power Press, 2006.

[3] Liu Zhenya. Uhv ac transmission system external insulation. China Electric Power Press, 2008.

[4] Wang Cangchang. Power equipment on-line monitoring and fault diagnosis. Qinghua univeraity press,2008.

[5] The electric power research institute artificial system. China Electric Power Press, 2008. 